\title{
В. В. ШЛЫЧКОВ
}

\section{И. К. КИЯМОВ}

С. М. КУЛИШ ${ }^{3}$

\section{Д. Р. НЕСТУЛАЕВА}

\section{И. Г. АЛАФУЗОВ ${ }^{4}$}

${ }^{1}$ Казанский национальный исследовательский технический университет им. А. Н. Туполева,

$$
\begin{gathered}
\text { 2. Казань, Россия } \\
{ }_{2}^{2} \text { Альметьевский государственный нефтяной институт, г. Казань, Россия } \\
{ }^{3} \text { Казанский государственный энергетический университет, г. Казань, Россия } \\
{ }^{4} \text { Журнал «Вестник эконолики, права и сочиологии», г. Казань, Россия } \\
\text { ОБ ОТДЕЛЬНЫХ АСПЕКТАХ ПРИМЕНЕНИЯ } \\
\text { «РУЧНОГО УПРАВЛЕНИЯ» ОРГАНАМИ РОССИЙСКОЙ } \\
\text { ГОСУДАРСТВЕННО-МУНИЦИПАЛЬНОЙ ВЛАСТИ }
\end{gathered}
$$

\section{ОБ ОТДЕЛЬНЫХ АСПЕКТАХ ПРИМЕНЕНИЯ «РУЧНОГО УПРАВЛЕНИЯ» ОРГАНАМИ РОССИЙСКОЙ ГОСУДАРСТВЕННО-МУНИЦИПАЛЬНОЙ ВЛАСТИ}

Цель: определение содержания и состава понятия «ручное управление»; анализ мотивов, правовых основ, легитимности, форм и методов использования «ручных процедур» в управленческом процессе органами государственномуниципальной власти Российской Федерации; определение соотношения «системных» и «ручных» методов в российской управленческой практике, а также оценка степени воздействия последних на социально-экономическую жизнь современного российского общества.

Методы: использовались широко применяемые в исследовательской деятельности методы: описательный, анализ и синтез, дедукция и индукция, обобщение, наблюдение, прогнозирование, научная абстракция, статистический анализ, системный анализ, а также приемы группировки и классификации, приемы сравнительного исторического и межотраслевого анализа, экспертные суждения. Совокупность данных методов позволила авторам обеспечить достоверность проведенного исследования и обоснованность его выводов.

Результаты: авторы сформулировали собственный вариант понятия «ручное управление»; выявили причины, условия и мотивы его применения российскими органами государственно-муниципальной власти; описали наиболее распространенные методы его применения, а также факторы увеличения случаев отказа от использования системных процедур в современной практике государственно-муниципального управления. Предложенные в работе выводы основываются на анализе существующего опыта применения «ручного управления» федеральными органами государственной власти, органами государственной власти Республики Татарстан и г. Москвы в разрешении проблемы обманутых дольщиков и регулировании процессов реконструкции и застройки Казани и Москвы в 2015-2016 гг.

Научная новизна: рассматривая практику российского государственно-муниципального управления, авторы акцентируют внимание на применяемых сегодня методах и процедурах его осуществления, таких как создание параллельных управленческих структур, переход к режиму прямых директивных указаний и т. д. На основании проведенного анализа практической деятельности органов власти субъектов РФ выявлено соотношение «ручных» и «системных» процедур в управленческом процессе, сформулировано определение понятия «ручное управление», раскрываются условия и мотивы его применения, а также делается вывод о том, что главной причиной применения и расширения практики «ручного управления» являются несовершенство и противоречивость действующего российского законодательства, которое, с одной стороны, не в полной мере отразило фундаментальные социально-экономические изменения, произошедшие в России за последние десятилетия, а с другой, - не всегда способно адекватно регулировать вновь возникшие отношения между субъектом и объектом в процессе практики государственно-муниципального управления. Практическая значимость: в результате исследования авторы прогнозируют возможные последствия наметившейся тенденции расширения практики «ручного управления» органов государственно-муниципальной власти как в среднесрочной, так и в долгосрочной перспективах. 
Ключевые слова: экономика и управление народным хозяйством; «ручное управление»; системное управление; субъект управления; объект управления; баланс прямых и обратных связей; органы власти; прямые директивные указания; непосредственное взаимодействие структур; виды государственно-муниципального управления; анализ практики «ручного управления»

Как цитировать статью: Шлычков В. В., Киямов И. К., Кулиш С. М., Нестулаева Д. Р., Алафузов И. Г. Об отдельных аспектах применения «ручного управления» органами российской государственно-муниципальной власти // Актуальные проблемы экономики и права. 2016. Т. 10, № 3. C. 39-54. DOI: http://dx.doi.org/10.21202/1993-047X.10.2016.3.39-54

\section{Введение}

Теория и практика государственного и муниципального управления современной России в последние десятилетия стали предметом пристального изучения общественно-политических наук, и по данной проблематике российскими исследователями был разработан научный понятийный аппарат, проведены серьезные исследования применяемых управленческих механизмов, опубликовано большое количество научных статей и монографий. Но, несмотря на значительный объем проделанной научным сообществом работы, отдельные аспекты государственного управления не получили должного научно-теоретического обоснования, оставаясь в зоне слабоизученных белых пятен современной отечественной науки. К подобной категории недостаточно исследованных российскими учеными проблем, по нашему мнению, относится и метод «ручного управления», который в последние годы получил достаточно широкое применение в практике государственно-муниципального управления России. Словосочетание «ручное управление» стало сегодня достаточно популярным и периодически используется в публичных выступлениях первых лиц российского государства, общественных деятелей, экспертов и представителей средств массовой информации. При этом само научное сообщество до настоящего времени так и не сформулировало единое и общепризнанное определение данного понятия, не выработало своего отношения к этому методу государственно-муниципального управления, а также оценке результатов его применения.

Не претендуя на полноту научного исследования заявленной проблемы, позволим себе в ограниченных рамках настоящей работы поделиться с читателями результатами наших размышлений о практике и легитимности «ручного управления» органов государствен- но-муниципальной власти и влиянии данного метода управленческого воздействия на социально-экономическое развитие отдельных регионов и России в целом.

\section{Результаты исследования}

1. Базовые понятия и основные категории общей теории управления

Несмотря на наличие множества трактовок и подходов к определению понятия «управление», как уже говорилось выше, авторам данной работы так и не удалось найти в научной литературе четко сформулированное, а главное, принятое большинством научного сообщества определение понятия «ручное управление» как его отдельной разновидности. Не вмешиваясь в научно-теоретические споры ученых-исследователей, глубоко погруженных в данную проблематику, позволим себе напомнить читателям наиболее общие подходы к определению понятия «управление», позволяющие впоследствии перейти к теоретическому анализу причин возникновения и практики применения «ручного управления» российскими органами государственно-муниципальной власти. В частности, «Большой экономический словарь» определяет управление как: 1) руководство, направление чьей-либо деятельности; 2) процесс планирования, организации, мотивации и контроля, необходимый для того, чтобы сформулировать и достичь целей организации ${ }^{1}$. Французский ученый Шардон Анри Файоль, разработчик 14 принципов, применяемых в системах государственного и муниципального управления, рассматривает управление как возможность «предвидеть и планировать, распоряжаться и мотивировать, координировать и контроли-

1 Азраилян А. Н. Большой экономический словарь. 7-е изд. М.: Ин-т новой экономики, 2010. 1472 с. 
ровать» [1]. А американский исследователь М. Фоллет определила целью управления «обеспечить выполнение работы с помощью других людей» [2]. Институт Всемирного банка под процессом управления подразумевает «использование политической власти для контроля-регулирования внутригосударственных дел» ${ }^{2}$. В свою очередь, один из ведущих российских научных авторитетов в данной области профессор Г. В. Атаманчук под государственным управлением понимает «сознательно организующее и регулирующее воздействие государства на общественную (публичную) жизнедеятельность людей в целях ее упорядочения, сохранения или преобразования» [3].

В теории управления используется значительное число научных категорий, из которых нас с учетом выбранного формата настоящей работы интересуют только несколько: субъект управления и объект управления, а также образуемые между ними прямые и обратные связи. В качестве субъекта управления нами рассматриваются обладающее необходимыми властными полномочиями конкретное лицо или формализованная структура, инициирующие взаимодействие с объектом управления и самостоятельно определяющие способы и приемы целенаправленного воздействия на него в целях сохранения, упорядочения и дальнейшего преобразования в направлениях, намеченных «субъектом» [4]. При этом «субъект управления» обладает не только полномочиями принимать те или иные управленческие решения, но и имеет возможность гарантировать их реализацию через соответствующий механизм, включающий в себя в том числе и меры принуждения. «Объектом управления» является то, на что направлено управляющее воздействие «субъекта», материальным воплощением чего может стать как отдельная личность, так и формализованная структура (организация, отрасль, государство и т. д.) [4, с. 145]. Вступая в управленческие отношения, субъект и объект создают системное взаимодействие и сопряжены между собой прямой и обратной связью. Процесс управления носит системный характер и, как любая система, представляет собой определенную совокуп-

2 The International Bank for Reconstruction and Development. URL: http://www-wds.worldbank.org/servlet/WDSContentServer/ IW3P/IB/1999/12/02/000178830_98101901364149/Rendered/PDF/ multi0page.pdf (дата обращения: 10.02.2016). ность взаимозависимых частей, каждая из которых влияет на характеристику целого.

Таким образом, понимая, что управление есть результат целенаправленного интеллектуального воздействия субъекта на объект с целью его качественного и количественного изменения, позволим себе сформулировать понятие «управление» как организующее и регулирующее воздействие на объект в целях его сохранения, упорядочения и дальнейшего преобразования в направлениях, намеченных субъектом.

2. «Ручное управление» как проявление нарушений баланса прямых и обратных связей между субъектом и объектом управленческого прочесса

Методика ООН, принятая в 1996 г., выделяет четыре вида государственного управления: политическое, административное, экономическое и системное. Несмотря на то, что каждый из них имеет собственный предмет регулирования, на практике управленческий процесс осуществляется фактически одними и теми же субъектами управления на основе единых правил и процедур, установленных российским и региональным законодательствами. При этом управленческие отношения, возникающие в любой из сфер государственного и муниципального регулирования, оказывают существенное влияние на весь комплекс общественных процессов, сознание и деятельность населения, так как на практике невозможно отделить политику от экономики или как-то исключить их воздействие на социальную среду ${ }^{3}$.

Анализируя реальные процессы, происходящие в России на всех уровнях государственно-муниципальной власти, можно с уверенностью констатировать факт того, что «ручное управление» как метод управляющего воздействия за последние десятилетия получил достаточно широкое распространение, составив серьезную конкуренцию процедурам регулирования социально-экономических процессов в «автоматическом режиме». Последнее понятие достаточно часто сравнивают с «автопилотом» - программно-аппаратным комплексом, автоматизирующим все этапы полета современного летательного аппарата. Принцип работы автопилота предусматривает «автоматическую

${ }^{3}$ Resolution adopted by the general assembly $50 / 225$ «Public administration and development» (A/50/L.69/Rev.1 and Rev.1/Add.1). URL: http://www.un.org/en/ga/search/view_doc. asp?symbol=A/ RES/50/225 (дата обращения: 10.02.2016). 
стабилизацию параметров движения летательного аппарата (автопарирование возмущений по курсу, крену и тангажу) и в качестве дополнительных функций стабилизацию высоты и скорости» [5]. Иначе говоря, применение подобного технического устройства позволяет обеспечивать заранее заданные параметры полета, корректируя в автоматическом режиме работу системы управления, адекватно реагируя на изменения внешних и внутренних условий на основе заложенных в программы алгоритмов.

Проводя аналогию с действующей российской системой государственно-муниципального управления, необходимо отметить тот факт, что на либеральнодемократической волне начала 90-х годов в ее основу был заложен именно системный подход, а «ручное управление» на первоначальном этапе рассматривалось в качестве исключительной или чрезвычайной меры, возможность применения которой была обусловлена возникновением нестандартных, а главное, непредвиденных обстоятельств. Однако в дальнейшем под влиянием, прежде всего, субъективных факторов российская система государственно-муниципального управления постепенно была переориентирована с «автоматических процедур» на возможность применения «ручных методов» регулирования протекающих в стране социально-экономических процессов, а практика применения «ручного управления» стала расширяться, охватывая практически все сферы регулирования.

Закрепленная в Конституции страны действующая система государственно-муниципального управления России является достаточно сложным комплексом иерархически связанных между собой государственных и общественных институтов, осуществляющих взаимодействие как по вертикали, так и на горизонтальном уровне, а действующая законодательная база достаточно детально регламентирует взаимоотношения между различными частями данного комплекса, определяя процедуры и правила их взаимодействия, объем компетенций каждого субъекта, а также перечень возможных методов и способов воздействия на управляемую социально-экономическую систему [6].

Функционируя в стабильных условиях, система государственно-муниципального управления должна обеспечить устойчивое развитие государства и общества, основанное на эффективном использовании потенциала страны и получении максимального социально-экономического эффекта за счет осуществле- ния стандартных мер и процедур, предусмотренных российским законодательством. Именно нормы права, принятые на основании глубокого анализа социальноэкономической жизни общества и с учетом интересов всех сторон управленческого процесса, должны выступать в качестве аналога компьютерных программ «автопилота» и обеспечивать не только эффективность управленческого воздействия на «субъекты», но и определять границы этого воздействия и набор применяемых для этого методов. В этом случае все участники законотворческого процесса должны стремиться к формированию национальной законодательной базы, отвечающей современным российским реалиям и «позволяющий адекватно реагировать на изменения внутренних и внешний условий, а также вновь возникающие риски и вызовы» [4, с. 146]. Фактически любой «субъект управления» в процессе принятия легитимного управленческого решения должен опираться на действующее законодательство, регламентирующее как объем его полномочий, так и перечень возможных форм и методов воздействия на «объект управления». При этом, не отрицая определенную степень влияния неформальных институтов на социально-экономические процессы, протекающие в современном российском обществе, авторы настоящей работы отдают приоритет государственно-правовой форме их регулирования, в полной мере разделяя мнение о том, что «эффективная правовая система необходимое условие успеха свободного рынка: без прав собственности нет мотивации для накопления, займа или инвестирования» [7, с. 282].

В нестабильном режиме функционирования государства (кризис, война, внешние санкции и т. д.) на первый план выходит требование результативности, которое достигается подчас за счет снижения экономической эффективности, демонтажа действующей системы управления и возникновения новых, параллельных и не всегда законных центров принятия управленческих решений. Подобные меры, безусловно, будут оправданы российским обществом в случаях, когда под угрозой находится сама возможность существования нашего государства или жизнь и безопасность его граждан [8]. Однако авторов данной работы не безосновательно беспокоят попытки отдельных «субъектов управления» расширительно толковать понятие «чрезвычайной ситуации», что позволяет им порой принимать те или иные управ- 
ленческие решения в обход установленных законом правил и процедур, т. е. осуществлять свою деятельность не на правовой, а на ситуационной основе. Так, проводимые в регионах проверки Счетной палаты РФ, органов ФАС и прокуратуры постоянно выявляют многочисленные факты нецелевого использования бюджетных средств или случаи их выделения подрядным организациям без проведения установленных законом конкурсных процедур. При этом чиновники, совершившие подобные противоправные действия, почти всегда мотивируют свои поступки необходимостью успеть провести ремонтно-строительные работы к какой-то юбилейной дате или приезду высоких гостей в регион или муниципалитет. Таким образом, рабочий визит президента РФ в тот или иной регион является для отдельных руководителей «чрезвычайной ситуацией», позволяющей по их логике принимать подобные управленческие решения исходя из принципа «целесообразности», что фактически приводит к ситуации, когда «соблюдение "формальных" демократических норм и процедур не считается чем-то первостепенным и обязательным» [9, с. 252].

Необходимый уровень эффективности управленческого процесса на практике обеспечивается за счет гармонизации и достижения баланса прямых и обратных связей между «субъектом» и «объектом». Анализ накопленного управленческого опыта наглядно демонстрирует факт того, что перекос в сторону прямых связей ведет к авторитарной бюрократизации управления и снижению его эффективности, а преобладание в управленческом процессе обратных связей приводит к потере контроля над управляемой социально-экономической системой и хаосу [10, с. 5]. Именно нарушение баланса подобных связей в сторону доминирования «прямых связей», по нашему мнению, является главной причиной расширения практики применения органами государственно-муниципальной власти методов «ручного управления».

3. Механизмы и процедуры «ручного управления». Определение понятия «ручное управление»

Какое же содержание вкладывают эксперты в термин «ручное управление» и какими способами «субъекты управления» обеспечивают применение «ручных процедур» в управленческом процессе?

Прежде всего, авторы настоящей работы полностью разделяют точку зрения руководителя направления «Финансы и экономика» Института современного развития Никиты Масленникова, рассматривающего ручное управление в России в качестве сложившейся «системы исключений из правил» ${ }^{4}$. Однако, бесспорно, правы и те представители научного сообщества, которые акцентируют свое внимание на механизмах применения «ручных процедур» и отмечают, что «Путин, как и два столетия назад российская императрица Екатерина Великая, не доверяя институтам, предпочитает осуществлять управление страной через доверенных лиц» [9, с. 258], выделяя данный принцип в качестве определяющего при формулировании понятия «ручное управление». Однако ради объективности необходимо сказать, что скептическое отношение некоторых государственных деятелей к действующим институтам разделяют многие ученые и эксперты. В частности, известный экономист Д. К. Норт считает что «институты не обязательно - и даже далеко не всегда - создаются для того, чтобы быть социально эффективными; институты или, по крайней мере, формальные правила создаются скорее для того, чтобы служить интересам тех, кто обладает достаточной силой для навязывания своих новых правил» [11].

Еще в 2002 г. российский специалист в области управления А. Прохоров обратил внимание научного сообщества на практику создания в стране параллельных управленческих структур, «наделенных обширными правами... причем эти права не уравновешены соответствующими обязанностями» [5, с. 202], назвав ее «уникальным ноу-хау русской модели управления» [5, с. 201]. Наличие подобных и не всегда легитимных образований позволяет принимать и реализовывать управленческие решения вне юридически оформленной системы и с нарушением установленных российским законодательством правил и процедур. Конкретные примеры осуществления «ручного управления» через создание параллельных структур будут нами рассмотрены ниже при анализе практики российских органов государственно-муниципальной власти.

Другим способом внедрения практики «ручного управления» в процесс регулирования социальноэкономический жизни российского общества является

${ }^{4}$ Полунин А. Греф намерен начать Перестройку 2.0. Поможет ли реформа госуправления поднять экономику РФ? // Свободная Пресса. 2016. 16 марта. URL: http://svpressa.ru/ economy/article/144471/ (дата обращения: 15.04.2016). 
переход от процедур системного взаимодействия элементов управляющего комплекса к режиму прямых директивных указаний и практике непосредственных посылов от вышестоящих руководителей к низшим элементам управляемой системы. При этом, к сожалению, достаточно часто вышестоящие органы власти ставят перед подчиненными структурами задачи, выходящие за рамки компетенции последних, априори сознавая, что легитимно решить данную проблему в рамках существующего правового поля просто невозможно. Как следствие, получив подобный посыл, субъект управления вынужден искать способы решения проблемы именно через «ручные процедуры» и без опоры на действующее законодательство.

Одновременно в последние годы мы наблюдаем отчетливую тенденцию расширения практики делегирования не обеспеченных финансами полномочий федеральных органов власти на региональный и муниципальный уровни. Как следствие, получив не подкрепленные финансовыми ресурсами полномочия, региональные и муниципальные власти вынуждены брать на себя ответственность за состояние тех или иных сфер социально-экономической жизни общества, не имея при этом возможности воздействовать на объект регулирования в рамках стандартных процедур, или, проще говоря, полностью профинансировать обязательства государства, тем самым обеспечив их исполнение в полном объеме 5 . Фактически в условиях ограниченности финансовых ресурсов федеральные органы власти ставят перед региональными и муниципальными властями задачу обеспечения исполнения государственных функций не только через прозрачные и легитимные механизмы, но и в определенной мере за счет использования авторитета власти, конвертируя потенциальную возможность применения мер государственного принуждения в конкретные экономические преференции, используя для этого внерыночные процедуры «ручного управления» $[12,13]$.

Кроме того, авторы настоящей работы неоднократно сталкивались с многочисленными случаями добровольного отказа чиновников от своих полномочий

\footnotetext{
5 Тимофеев Р. А., Шлычков В. В., Алафузов И. Г. Актуальные вопросы функционирования региона как социально-экономической системы // Актуальные проблемы экономики и права. 2015. № 3. C. 63-70.
}

и переноса по их инициативе решения обсуждаемой проблемы через несколько иерархических ступеней в более высокую инстанцию. Подобные бюрократические приемы позволяют чиновникам, с одной стороны, постоянно быть на виду у вышестоящего руководства, усердно разрешая спровоцированные ими же якобы актуальные проблемы, а с другой стороны, уклониться от любой персональной ответственности за возможные неудачи, умело разделив с вышестоящим руководством возможные риски.

Все вышесказанное позволяет определить «ручное управление» как проявление кризиса государственных и общественных институтов и деформации существующей модели российского государственно-муниципального управления, заключающиеся в нарушении баланса установленных законодательством внутренних и внешних связей между субъектом управления и управляемыми им объектами различных уровней, проявляющиеся в создании параллельных центров принятия властных решений и переходе от системного взаимодействия элементов управляющего комплекса к режиму прямых директивных указаний, в нарушениях установленных иерархических связей элементов системы управления и расширении практики непосредственного взаимодействия вышестоящих структур с нижестоящими, позволяющей субъекту управления принимать решения на ситуационной основе, исходя из принципа «целесообразности» и «личного усмотрения» без учета законодательных требований и с нарушением определенных законом процедур [4, с. 148].

4. Анализ практики «ручного управления» российской государственно-муниципальной власти

Анализ существующей практики государственного управления наглядно показывает преобладание «автоматических процедур» в управленческом процессе российских органов власти. Как правило, в «автоматическом режиме» рассматриваются рутинные и текущие вопросы, алгоритм решения которых давно отработан в рамках традиционных практик и процедур, и, как правило, это вопросы второго плана или же процесс их разрешения жестко регламентирован действующим законодательством. Если же орган власти сталкивается с нестандартной ситуацией, с необходимостью оперативно отреагировать на вновь возникшие угрозы и вызовы, то переход на «ручной режим» управления в реальной жизни достаточно 
часто является единственным способом разрешения заявленной проблемы.

В период легитимного перехода власти от первого российского президента к В. В. Путину в 2000 г. последний в дополнение к закрепленной в Конституции системе государственного управления своим Указом № 849 от 13.05.2000 г. образовал в России федеральные округа. При этом назначаемые лично президентом РФ полпреды вошли в структуру Администрации Президента РФ, что значительно увеличило политический вес этой, в принципе, чисто аппаратной структуры и позволило ей конкурировать по степени влияния на общероссийские общественно-политические процессы с правительством РФ. Фактически был создан параллельный Правительству самостоятельный механизм управления регионами, полностью встроенный в «вертикаль личной власти» президента, который, в свою очередь, делегировал полпредам часть своих полномочий и начал управлять страной через доверенных лиц, т. е. в значительной степени перешел на «ручное управление».

В дальнейшем высшие руководители страны неоднократно применяли «ручные процедуры» в процессе управления российским государством. Достаточно вспомнить события 2009 г. в городе Пикалево [14, с. 2; 15 , с. 424], когда в ответ на протесты 16-тысячного населения глава правительства был вынужден лично выехать непосредственно на место событий и путем прямого давления на собственников добиться урегулирования экономического спора трех хозяйствующих субъектов, приведшего к фактическому закрытию производства и увольнению каждого третьего жителя' ${ }^{6}$ Из-за системных ошибок, допущенных в 2004 г. при проведении приватизации градообразующего предприятия «Пикалевское объединение "Глинозем”, данный единый технологический комплекс был искусственно разделен на три производства и продан разным юридическим лицам, не сумевшим в дальнейшем согласовать свои интересы в рамках стандартных рыночных процедур. Фактически сложившаяся вокруг предприятия ситуация являлась не чем иным, как market failure ${ }^{7}$, т. е. проявлением сбоя в рыночном

\footnotetext{
6 Отметим, что в зарубежной практике в отдельных странах вводились специальные меры по защите увольняемых, в частности в США [16].

7 Понятие market failure было введено Ф. Батором [17].
}

механизме в условиях поиска оптимального решения лишь для рыночных агентов без учета интересов локального сообщества моногорода [18, с. 276, 277; 19 , с. $179 ; 20$, с. 717]. К сожалению, как уже ранее отмечалось авторами работы, законодательная база современной России далека от совершенства и наработанный опыт правоприменения пока еще не позволяет эффективно разрешать подобные конфликты в рамках системных процедур, точно так же, как и неформальные институты на данном этапе своего развития не способны оказать определяющего воздействия на стороны конфликта. Фактически только примененные премьер-министром «ручные процедуры» позволили достаточно результативно привести сложившуюся ситуацию к экономическому оптимуму, что явилось достаточно серьезным аргументом в обосновании оправдания вмешательства государства в экономические процессы. Однако, по нашему мнению, ситуация пикалевского market failure была только поводом, а не причиной применения федеральной властью «ручного метода». Истинной причиной, на наш взгляд, является отсутствие альтернативных эффективных системных механизмов и способов преодоления подобных противоречий многочисленными участниками рынка и нахождения баланса их интересов в рамках согласительных процедур, основанных на нормах права или общепринятых традициях.

Какими же достижениями может гордиться действующая система государственно-муниципального управления? Анализ, проведенный авторитетными экспертами в области управления, наглядно выявил тренд лавинного увеличения прямых поручений президента РФ за последние 5-6 лет. Сухие цифры говорят о «ежегодном росте подобных поручений на 33-37 \%, причем на 1000 распоряжений российского президента приходится в среднем 32 распоряжения президента американского» ${ }^{8}$, что, по нашему мнению, является весьма сомнительной победой российской бюрократии. Независимые эксперты и отдельные государственные чиновники не раз заявляли о необходимости пресечения практики непосредственного обращения глав регионов и муниципальных образо-

8 Полунин А. Греф намерен начать Перестройку 2.0. Поможет ли реформа госуправления поднять экономику РФ? // Свободная Пресса. 2016. 16 марта. URL: http://svpressa.ru/ economy/article/144471/ (дата обращения: 15.04.2016). 
ваний, руководителей ведомств всех уровней и представителей крупного бизнеса к президенту и премьерминистру с заведомо непроходными проектами или предложениями, получившими ранее отрицательные заключения со стороны экспертного сообщества или соответствующих профильных органов государственной власти. Однако сложившиеся традиции и существующая модель государственно-муниципального управления позволяют на практике нарушать установленные законодательством иерархические связи, предоставляя отдельным лицам возможность подчас в прямом смысле в «ручном режиме» (что называется «из рук в руки») лично передать свои обращения главе государства или председателю правительства. Высшие руководители страны, в свою очередь, переадресовывают подобные проекты соответствующим федеральным органам государственной власти уже в качестве официального поручения, которое автоматически берется на контроль соответствующими структурами. Результатом подобной порочной практики является отвлечение значительных ресурсов на повторную проработку уже ранее рассмотренных и отклоненных проектов и предложений, что, безусловно, негативно влияет на эффективность работы всего государственного аппарата и влечет за собой ничем не обоснованный рост издержек процесса государственно-муниципального управления.

В свою очередь, главы регионов практически полностью копируют управленческую практику федеральных органов государственной власти и применяют в процессе управления аналогичные процедуры и методы, включая практику «ручного регулирования». В настоящее время официальная оценка деятельности региональной исполнительной власти проводится в соответствии с Указом № 1199 «Об оценке эффективности деятельности органов исполнительной власти субъектов Российской Федерации» от 21.08.2012, которым утвержден перечень из 12 показателей, один из которых (доля выпускников школ, не сдавших ЕГЭ) впоследствии был отменен9. Анализ оставшихся 11 показателей достаточно крас-

9 Указ Президента РФ № 1199 «Об оценке эффективности деятельности органов исполнительной власти субъектов Российской Федерации» (с изменениями и дополнениями) от 21.08.2012 // Собрание законодательства Российской Федерации. 2012. № 35. Ст. 4774. норечиво говорит о том, что на исполнительную власть регионов и их руководителей возлагается ответственность за достаточно широкий круг вопросов: от поддержки предпринимательства и привлечения инвестиций до проблем с социальной защитой детей, оставшихся без попечения родителей.

Однако в общественном сознании и на практике глава российского региона несет ответственность фактически за все, что происходит на территории соответствующего субъекта федерации, вне зависимости от объема компетенций и уровня полномочий, предоставленных ему действующим законодательством, которое в неполной мере отразило фундаментальные изменения социально-экономической жизни России конца XX и начала XXI вв. Так, традиционно и без оглядки на закон часть общества продолжает возлагать на государственную власть субъекта федерации ответственность за деятельность транспортных, промышленных и торговых предприятий, расположенных в регионе, несмотря на то, что большинство из них прошли процедуру приватизации и уже многие годы принадлежат частным лицам или негосударственным компаниям.

Точно так же и федеральная власть продолжает по инерции ставить перед регионами вопросы, находящиеся вне их компетенции, не подкрепляя их при этом соответствующими ресурсами. Ярким примером подобной практики может служить поручение президента РФ В. В. Путина главам регионов решить проблему обманутых дольщиков. Исполняя прямое поручение главы государства, региональная власть, формально не являясь стороной гражданско-правовых отношений и договоров долевого строительства, фактически вынуждена, используя свой «административный ресурс», изыскивать значительные финансовые средства для достройки проблемных домов или находить формы компенсации издержек вновь привлеченным подрядным организациям. Решить подобную задачу в рамках действующего законодательства просто невозможно, а значит, только применение «ручных процедур» позволит региональной власти исполнить данное поручение. Например, в Казани и Набережных Челнах к процессу достройки проблемного жилья были привлечены новые подрядные организации, согласившиеся за свой счет завершить строительно-монтажные работы в обмен на обещание региональной власти и муниципалитетов выделить 
им вне установленных законом конкурсных процедур наиболее привлекательные земельные участки для жилищного строительства. При этом надо понимать, что подобные, мягко говоря, не до конца безупречные в правовом плане решения принимаются главой региона или муниципалитета вполне осознанно, по принципу выбора меньшего из двух зол.

Точно так же региональная или муниципальная исполнительная власть решает и другие нестандартные проблемы, мотивируя экономических агентов к нужным ей действиям иногда через неофициальный механизм предоставления тех или иных льгот и преференций, а иногда и через «процесс убеждения», который достаточно часто выражается в прямом административном давлении, получить защиту от которого хозяйствующему субъекту практически невозможно [21]. Например, ночью 9 февраля 2016 г. в Москве власти города снесли 97 объектов так называемого самостроя - ларьков и торговых павильонов, расположенных вблизи станции метро, самостоятельно определив перечень из 104 объектов, подлежащих сносу. При этом в федеральных и региональных СМИ была развернута мощная пропагандистская кампания в оправдание действий московских властей, общий информационный фон которой говорил о якобы безоговорочной поддержке этих шагов москвичами. Проведенное 12 февраля 2016 г. РБК журналистское расследование показало, что на момент ночного сноса 97 павильонов и ларьков собственники 48 из них уже подтвердили в суде законность своего нахождения на занимаемых землях, по 27 объектам дела еще были в стадии судебного разбирательства и только в отношении 3 (!) ларьков московская мэрия имела судебные решения, дающие ей право отнести их к категории самостроя [22]. Фактически все мы стали свидетелями открытого государственного внесудебного захвата и уничтожения частной собственности, поддержанного населением, что явно негативно скажется на инвестиционной и предпринимательской активности экономических агентов, в очередной раз убедившихся в «равенстве всех перед законом». И, как мы понимаем, решение о включении в перечень самостроя тех или иных объектов московские власти приняли келейно в рамках тех же «ручных процедур», отказавшись от процесса переговоров с собственниками и без учета мнения судебной власти, в подавляющем большинстве случаев вставшей на сторону собственников.
Другим не менее ярким примером «ручного управления» может являться существующая в Казани с 2014 г. достаточно своеобразная практика контроля за ходом реконструкции старых и строительства новых объектов столицы Татарстана. Исключительно в выходные или праздничные дни президент республики Р. Н. Минниханов совершает «неофициальные» прогулки по тем или иным районам города в сопровождении мэра и группы региональных и городских чиновников, включая прокурора РТ. Во время подобных прогулок непосредственно на месте принимаются решения об одобрении или замораживании тех или иных строительных проектов, определяются подрядчики будущих работ и контролируется ход текущего строительства на объектах, вне зависимости от вида их собственности или источников финансирования. Причем запрещены или заморожены на неопределенный срок были проекты, в полном объеме прошедшие установленную законом процедуру согласования проектно-сметной документации и получившие разрешения на строительство от муниципальных властей города Казани. Однако, оценив на месте настрой руководителя региона, подавляющее большинство чиновников не стали отстаивать свою позицию по обсуждаемым вопросам и отказались от своих согласующих подписей на проектной и разрешительной документации, фактически признав как свою профессиональную некомпетентность, так и неэффективность возглавляемых ими институтов. Частота и формат подобных прогулок не прописаны ни в одном официальном документе и прямо зависят от загруженности руководителя региона и его настроения, при этом принимаемые в их рамках решения оказывают значительное влияние на развитие столицы Татарстана и работу строительного комплекса всей республики. Фактически в рамках «ручных процедур» узким кругом уважаемых, но не уполномоченных на это лиц отменяются легитимные решения органов государственной или муниципальной власти, принятые последними в рамках их компетенции, а консолидированное мнение представителей профессионального сообщества (Градостроительный совет, Управление архитектуры и т. п.) просто игнорируется. Кроме того, заинтересованные лица, считающие себя пострадавшими от незаконных, по их мнению, действий региональной власти, лишены возможности обжаловать ущемляющие их права и законные интересы решения 
как в суде, так и в вышестоящих органах, так как формально юридически никаких официальных решений в рамках «строительных прогулок» принято не было, а значит, и отсутствует предмет для обжалования действий непосредственно президента РТ. Впоследствии экономические агенты, чьи права или законные интересы были нарушены, вынуждены добиваться отмены подобного решения, вступая в юридический спор с оформившим его органом власти, хотя всем заинтересованным сторонам прекрасно известно, кто и когда его фактически принял.

В качестве очередного факта применения «ручных процедур» региональными органами государственной власти может служить ситуация с назначением в марте 2015 г. помощником президента РТ «на внештатной основе» госпожи Н. Л. Фишман (отвечающей в Татарстане за благоустройство и озеленение парков и скверов, а также реализацию программы Года водоохранных зон) и созданием под ее курированием некой региональной координационной комиссии с неопределенным правовым статусом. Столь высокая должность, кредит личного доверия президента РТ и организованное в региональных СМИ соответствующее информационное сопровождение ее деятельности позволяют сегодня 26-летней девушке фактически определять направления использования 2 млрд руб. бюджетных средств, подчас полностью игнорируя мнения избранных народных депутатов и авторитетных специалистов, высказывающих альтернативные точки зрения. Как нам кажется, при наличии в структурах региональной власти Министерства строительства, архитектуры и ЖКХ, Министерства экологии и природных ресурсов, Министерства лесного хозяйства и многих других ведомств, вся работа по благоустройству парков и скверов, а также проводимые водоохранные мероприятия должны проводиться в рамках системного взаимодействия вышеуказанных региональных органов и соответствующих муниципалитетов, а выделенные на эти цели соответствующие бюджетные средства должны дойти до получателя через стандартные процедуры, предусмотренные российским законодательством, включая утверждение расходов региональным парламентом. Несмотря на важность курируемых помощником президента РТ Н. Л. Фишман вопросов, авторы данной работы выступают против расширения практики создания «специальных или чрезвычайных» комиссий по отдельным социально-экономическим проблемам, отдавая приоритет повышению эффективности деятельности существующих системных государственных и общественных институтов. Тем более что российский опыт государственного управления неоднократно демонстрировал нам факты того, что, как правило, именно системные органы государственно-муниципальной власти впоследствии вынуждены были принимать на себя все негативные издержки от решений всевозможных «одноразовых» и «чрезвычайных» комиссий и комитетов после прекращения деятельности последних. Так, после ликвидации Дальневосточной дирекции Минрегиона РФ, созданной специально под саммит АТЭС 2012 г. во Владивостоке, все расходы и ответственность по завершению строительно-монтажных работ фактически легли на администрации Приморья и муниципальные власти города Владивостока. В частности, из краевого бюджета в течение последующих трех лет были направлены значительные средства на достройку двух пятизвездочных отелей «Хаятт», а мэрия Владивостока вынуждена была понести многомиллионные расходы по достройке дорожной инфраструктуры [23]. При этом надо иметь в виду, что все выделенные средства были консолидированы за счет сокращения других, не менее социально важных статей краевого и городского бюджетов, а первоначально принятые Дальневосточной дирекцией Минрегиона РФ решения о направлениях использования бюджетных средств практически не учитывали мнение и позицию депутатов законодательного собрания края и городского совета по данному вопросу.

\section{Выводы}

«Ручное управление» в последние десятилетия стало самостоятельным методом государственномуниципального управления и на практике широко применяется всеми органами государственной власти России, подчас оказывая на социально-экономическую жизнь общества неоднозначное влияние. Не найдя возможности разрешить тот или иной вопрос в рамках действующего законодательства и при помощи системных процедур, субъект управления, нарушая иерархию существующих связей, вынужден обращаться непосредственно к низшим элементам системы управления уже в режиме прямых директивных указаний, при этом достаточно часто ставя перед ними задачи, выходящие 
за пределы их компетенции и не обеспечивая последних необходимыми полномочиями и ресурсами.

К достоинству «ручных процедур» определенно можно отнести их относительную результативность в краткосрочной перспективе и возможность быстрого получения необходимого управленческого эффекта, который достигается за счет установления непосредственного взаимодействия элементов различного уровня единого управляющего комплекса и исключения из управляющего процесса отдельных функций и процедур, таких как контроль или оценка возможных последствий экспертным сообществом. Явными недостатками «ручного управления» мы должны однозначно считать негативные последствия, получаемые в средней и долгосрочной перспективе от реализации не полностью оцененных и не до конца просчитанных волюнтаристских управленческих решений, а также необоснованно высокие затраты на достижение запланированных результатов.

О подобной опасности переоценки своих возможностей и недооценки отдаленных последствий сиюминутного успеха предупреждал еще Ф. Энгельс, который писал, что «не будем, однако, слишком обольщаться нашими победами над природой. За каждую такую победу она нам мстит. Каждая из этих побед имеет, правда, в первую очередь те последствия, на которые мы рассчитывали, но во вторую и третью очередь совсем другие, непредвиденные последствия, которые очень часто уничтожают значение первых» [24, с. 495-496].

По нашему мнению, переход к «ручному управлению» в период чрезвычайных ситуаций и чрезвычайных обстоятельств может быть оправдан, и даже более того, может являться единственно возможным эффективным методом государственно-муниципального управления [25]. Однако российское общество должно понимать, что сам термин «чрезвычайный» может по-разному трактоваться в той или иной ситуации. Так, достаточно обоснованным будет применение «ручных процедур» в управленческом процессе в период военной агрессии или стихийного бедствия, когда вопрос стоит о спасении человеческой жизни или государственной безопасности. Но можно ли считать чрезвычайной ситуацию, создавшуюся после введения экономических санкций в отношении России? Как нам кажется, нет, так как в определенном смысле антироссийские санкции являются логическим продолжением борьбы держав за мировое политическое и экономическое господство и одной из форм конкурентной борьбы за рынки и сферы влияния, которую российская государственно-муниципальная власть должна вести в рамках системных процедур, рассматривая ее в качестве стандартной функции государственного управления.

Несмотря на результативность применения «ручных процедур» в процессе управления и наличие на первоначальном этапе положительного эффекта их применения, в средне- и долгосрочной перспективах этот эффект, как правило, нивелируется как за счет объективной оценки реальных социально-экономических издержек и сопоставления их с достигнутыми результатами, так и за счет репутационных потерь от применения органами государственной и муниципальной власти нелегитимных методов и процедур (снижение инвестиционной и экономической активности, ухудшение предпринимательского климата и т. д.).

На наш взгляд, главной причиной применения и расширения практики «ручного управления» являются несовершенство и противоречивость действующего российского законодательства, которое, с одной стороны, не в полной мере отразило фундаментальные социально-экономические изменения, произошедшие в России за последние десятилетия, а с другой, не всегда способно адекватно регулировать вновь возникшие отношения между субъектом и объектом в процессе практики государственно-муниципального управления [26]. Если страны евродемократии на протяжении столетий формировали свою правовую систему исходя из принципов разделения властей, равенства всех перед законом и неприкосновенности частной собственности, а их граждане полностью разделяют и принимают эти ценности, то современная российская культура частной собственности и предпринимательства насчитывает всего четверть века, и реальные настроения большинства населения страны пока далеки от базовых ценностей, провозглашенных и закрепленных в действующей Конституции России. Как нам кажется, причиной этого является не только относительная «живучесть» у части россиян навязанных прежней коммунистической идеологией догм и стереотипов (неприятие частной собственности, стремление к государственному регулированию всех сфер общественной жизни и т. д.), но и серьезные просчеты в государственной политике последних десятилетий. Ведь ни для кого не является секретом факт того, что общество до сих пор не одо- 
брило (и, видимо, уже никогда не одобрит) процедуру приватизации 90-х годов, залоговые аукционы и многие другие действия политического руководства России, формально совершенные в рамках действующего законодательства, но не получившие легитимной поддержки населения из-за их несоответствия «общепринятым нормам и ценностям» [27]. Значительная часть россиян до сих пор имеют, на наш взгляд, достаточно обоснованные претензии к государственной власти, что объективно позволяет поставить под сомнение легитимность значительной доли важнейших для страны социально-политических и экономических решений на основании того, что они были приняты без «опоры на народный консенсус». Подобные латентные общественные противоречия между существующими на сегодня в российском обществе 10 стратами [28] существенно затрудняют дальнейшее социально-экономическое развитие государства, являясь серьезным дестабилизирующим фактором жизни общества.

Давая оценку подобной ситуации, нобелевский лауреат по экономике 1993 г. Дуглас Сесил Норт в своей Нобелевской речи, озаглавленной «Функционирование экономики во времени», отмечал, что «чрезвычайно трудно, да и практически недостоверно анализировать переход от плановой экономики к рыночной без институционального подхода к проблемам и событиям». Признанный ученый акцентирует внимание на том факте, что если «законы могут быть изменены в течение короткого времени, то неформальные нормы меняются постепенно, и именно такие нормы создают легитимную основу для действия законов, а революционные изменения последних часто приводят к результатам, отличающимся от ожидаемых» [11].

Действующий президент РФ В. В. Путин в целом положительно оценивает результаты применения «ручных процедур» и называет «ручное управление» принципом, который еще лет 15-20 будет определять российскую систему, прежде чем она сможет работать «в автоматическом режиме» ${ }^{10}$, что позволяет нам предположить дальнейшее расширение практики «ручного управления» на всех уровнях государственно-муниципальной власти России, несмотря на наличие определенных негативных последствий его применения. Однако уже сегодня политическое

${ }^{10}$ Гордеев И. Это правда он // Время новостей. 2007. 19 октября. URL: http://www.vremya.ru/2007/192/4/189565.html (дата обращения: 15.02.2016). руководство страны начало подготовку к масштабной реформе существующей системы управления, целью которой является «переход от ручного управления к проектному» ${ }^{11}$. По замыслу главы Сбербанка Германа Грефа, возглавившего рабочую группу по разработке реформы, необходимо создать единый федеральный центр управления реформами и реализации ключевых проектов во главе с президентом РФ, который бы периодично оценивал эффективность работы министерств и лично их руководителей по формированию и реализации конкретных приоритетных проектов на основании 5-7 целевых показателей и с учетом мнения международных экспертов. Практическая реализация подобных мер фактически вызовет управленческую революцию, которая приведет к значительным «жертвам» среди российских чиновников, включая команду президента, так как определенная часть государственного аппарата, по нашему глубокому убеждению, просто не способна эффективно работать в условиях общих «системных правил и процедур» и введение всеобъемлющего многоступенчатого и объективного государственного и общественного контроля за их деятельностью публично продемонстрирует их некомпетентность. Хватит ли у главы государства политической воли для начала подобных коренных преобразований, мы сможем увидеть уже в ближайшее время. Пока же мы вынуждены констатировать факт того, что к разработке ключевой для страны реформы системы управления традиционно привлечен ограниченный круг «доверенных и проверенных» экспертов, что неизбежно приведет к ситуации, когда основополагающие документы и принципы столь значимой для государства предполагаемой реформы будут разработаны без учета мнения значительной части российского научно-экспертного сообщества.

\section{Список литературы}

1. Fayol H. Administration industrielle et générale Paris: Dunod, 1999 [1916]. 133 c.

2. Follett M. P. The new state: Group organization the solution of popular government. Penn State Press, 1918. 379 p.

3. Атаманчук Г. В. Теория государственного управления: курс лекций. М.: Омега-Л, 2010. 525 с.

${ }^{11}$ Полунин А. Греф намерен начать Перестройку 2.0. Поможет ли реформа госуправления поднять экономику РФ? // Свободная Пресса. 2016. 16 марта. URL: http://svpressa.ru/ economy/article/144471/ (дата обращения: 15.04.2016). 
4. Шлычков В. В. «Ручное управление» как проявление институционального кризиса и деформации существующей модели российской экономики // Вестник экономики, права и социологии. 2015. № 4. С. 144-149.

5. Прохоров А. П. Русская модель управления. 3-е изд. М.: Изд-во Студии Артемия Лебедева, 2014. 496 с.

6. Shlychkov V., Nestulaeva D. Economic Science and Evolution of Economic Agents' Expectations Formation Process // Asian Social Science. 2015. № 11 (19). Pp. 82-89. DOI:10.5539/ass.v11n19p82

7. King S. D. Losing control: the emerging threats to Western prosperity. Yale University Press, 2010. 304 p.

8. Хасанова А. Ш., Ведин Н. В. К вопросу о формировании новой экономической парадигмы // Вестник экономики, права и социологии. 2014. № 4. С. 106-111.

9. RjabowA. Das Scheitern der demokratischen Transformation Russlands: war es unausweichlich? // Trendbericht Russland: Bilanz des letzten Jahrzehnts (1998-2008) und Perspektiven: ein Sammelband. Moscow: Rosspjen, 2010. C. 248-271.

10. Исаев А., Кадышев Е. Формирование актуальных принципов государственного управления и регулирования региональной экономики // Управление экономическими системами: электронный научный журнал. 2012. № 38. С. 5. URL: http:/uecs.ru/uecs-38-382012/item/1049-2012-02-17-1046-49 (дата обращения: 16.04.2016).

11. North D. C. Economic performance through time // The American economic review. 1994. T. 84, № 3. C. 359-368.

12. Shlychkov V. V., Khasanova A. S., Vedin N. V. A Quarter Century of Reform of the Russian Economy: Is it Wandering in a Maze or Jogging in Place? // Indian Journal of Science and Technology. 2015. No. 8 (10). DOI: 10.17485/ijst/2015/ v8iS10/84883. URL: http://www.indjst.org/index.php/indjst/ article/view/84883/65853 (дата обращения: 16.04.2016).

13. Bataykin P. A., Khasanova, A. Sh., Shlychkov, V. V., Toumashev A. R., Toumasheva M. V. Economic Growth in the Conditions of Resource Constraints: Ordinal Approach to Optimization of Macroeconomic Production Structure // Journal of Applied Economic Sciences. 2016. T. XI, № 3 (41) C. 521-531.

14. Aron L. Russia's 'Monotowns' Time Bomb // American Enterprise Institute for Public Policy Research. October. 2009. T. 19.

15. Teague E. How did the Russian population respond to the global financial crisis? // Journal of Communist Studies and Transition Politics. 2011. T. 27, № 3-4. C. 420-433.

(С Шлычков В. В., Киямов И. К., Кулиш С. М., Нестулаева Д. Р., Алафузов И. Г., 2016.

\section{Информация об авторах}

Шлычков Валерий Владимирович, доктор экономических наук, профессор, профессор кафедры «Экономическая теория», Казанский национальный исследовательский технический университет им. А. Н. Туполева

Адрес: 420111, Казань, ул. К. Маркса, 10, тел.: +7 (843) 238-15-93

E-mail: shlichkov_valery@mail.ru

ORCID: http://orcid.org/0000-0002-3307-2153

Researcher ID: http://www.researcherid.com/rid/D-4695-2016
16. Addison J. T., Blackburn M. L. Policy watch: The worker adjustment and retraining notification act // The Journal of Economic Perspectives. 1994. T. 8, № 1. C. 181-190.

17. Bator F. M. The anatomy of market failure // The quarterly journal of economics. 1958. C. 351-379.

18. Hazen T. L. Corporate Persona, Contract (and Market) Failure, and Moral Values, The // NCL Rev. 1990. T. 69. C. 273.

19. Coleman J. L. Rational Choice Approach to Legal Rules, The // Chi.-Kent L. Rev. 1989. T. 65. C. 177.

20. Kraus J. S., Coleman J. L. Morality and the theory of rational choice // Ethics. 1987. T. 97. № 4. C. 715-749.

21. Алафузов И. Г. Общественная поддержка как ключевой фактор эффективности антикризисных мер правительства РФ // Вестник экономики, права и социологии. 2015.

22. Серегин В., Штыкина А., Ткачёв И., Милюкова Я. Ошибка 104: почему суды признали снесенные Москвой строения законными. URL: http://www.rbc.ru/ins/business /11/02/2016/56bc77f69a79477ba00be719 (дата обращения: 18.02.2016).

23. Авченко В. Полный АТЭС // Expert Online. 09.09.2013. URL: http://expert.ru/2013/09/9/polnyij-ates/ (дата обращения: 16.03.2016).

24. Энгельс Ф. Диалектика природы / Маркс К., Энгельс Ф. Сочинения. М.: Политиздат, 1961. С. 339-626.

25. Батайкин П. А. Направления структурных сдвигов в национальной экономике // Вестник экономики, права и социологии. 2012. № 4. С. 20-22.

26. Тимофеев Р. А., Кулиш С. М. Формирование комплексного потенциала региональной экономической системы // Научное обозрение. 2011. № 3. С. 3-11.

27. Тумашев А. Р., Тумашева М. В. Социально-экономическое развитие России и задачи инвестиционной политики // Экономический вестник Республики Татарстан. 2014. № 4. C. $12-22$.

28. Gorschkow M. Soziale und politische Wandlungen im Transformationsland Russland // Trendbericht Russland: Bilanz des letzten Jahrzehnts (1998-2008) und Perspektiven: ein Sammelband. Moscow: Rosspjen, 2010. Pp. 406-420.

Дата поступления 21.06.2016 Дата принятия в печать 28.08.2016 Дата онлайн-размещения 20.09.2016 № 1. С. 13-15. 
Киямов Ильгам Киямович, доктор экономических наук, профессор, заведующий кафедрой «Промышленная теплоэнергетика», Альметьевский государственный нефтяной институт

Адрес: 423450, г. Альметьевск, ул. Ленина, 2, тел.: +7 (8553) 31-00-04

E-mail: kiyamov.ilgam@mail.ru

ORCID: http://orcid.org/0000-0003-2955-777X

Researcher ID: http://www.researcherid.com/rid/L-7898-2016

Кулиш Сергей Михайлович, кандидат экономических наук, доцент кафедры «Менеджмент», Казанский государственный энергетический университет

Адрес: 420066, Казань, ул. Красносельская, 51, тел.: +7 (843) 519-42-91

E-mail: kulishsm@yandex.ru

ORCID: http://orcid.org/0000-0002-7392-1340

Researcher ID: http:/www.researcherid.com/rid/D-4942-2016

Контактное лицьо:

Нестулаева Диана Рустамовна, кандидат экономических наук, доцент кафедры «Менеджмент», Казанский государственный энергетический университет

Адрес: 420066, Казань, ул. Красносельская, 51, тел.: +7 (843) 519-42-91

E-mail: diana_n_r@mail.ru

ORCID: http://orcid.org/0000-0002-4885-449X

Researcher ID: http:/www.researcherid.com/rid/D-4945-2016

Алафузов Игорь Григорьевич, кандидат экономических наук, заместитель главного редактора, журнал «Вестник экономики, права и социологии»

Адрес: 420015, Казань, ул. К. Маркса, 51а, тел.: +7 (843) 238-15-93

E-mail: vestnik eps@mail.ru

ORCID: http://orcid.org/0000-0001-8647-9603

Researcher ID: http:/www.researcherid.com/rid/D-4958-2016

\section{V. SHLYCHKOV}

\section{K. KIYAMOV ${ }^{2}$}

\section{S. M. KULISH}

\section{R. NESTULAEVA}

\section{G. ALAFUZOV ${ }^{4}$}

${ }^{1}$ Kazan National Research University named after A. N. Tupolev, Kazan, Russia

${ }^{2}$ Almetyevsk State Oil Institute, Kazan, Russia

${ }^{3}$ Kazan State Energy University, Kazan, Russia

" Journal "Bulletin of Economics, Law and Sociology”, Kazan, Russia

\section{ON SOME ASPECTS OF IMPLEMENTING THE "MANUAL CONTROL" BY THE BODIES OF THE RUSSIAN STATE-MUNICIPAL POWER}

Objective: to determine the content and structure of the concept of "manual control"; to analyze the motives, legal framework, legitimacy, forms and methods of "manual procedures" in management of state-municipal authorities of the Russian Federation; to determine the ratio of the "system" and "manual" methods in the Russian managerial practice, and to assess the impact of these methods on the socio-economic life of the modern Russian society.

Methods: the common research methods were used: descriptive method, analysis and synthesis, deduction and induction, generalization, observation, forecasting, scientific abstraction, statistical analysis, system analysis, and methods of grouping and classification, methods of comparative historical and interdisciplinary analysis, expert judgment. The combination of these methods allowed the authors to ensure the accuracy of the conducted research and the validity of its conclusions.

Results: the authors formulated their own version of the "manual control" concept; revealed the reasons, conditions and motives of its application by the Russian bodies of state-municipal power; described the most common methods of its application, as well as the factors of the increased

Шлычков В. В., Киямов И. К., Кулии С. М., Нестулаева Д. Р., Алафузов И. Г. Об отдельных аспектах применения ...

Shlychkov V. V., Kiyamov I. K., Kulish S. M., Nestulaeva D.R., Alafuzov I. G. On some aspects of implementing the "manual control” ... 
number of refusal to use the system procedures in contemporary practice of public management. The proposed conclusions are based on the analysis of the existing practice of the use of "manual control" by the federal public authorities, public authorities of the Republic of Tatarstan and Moscow in the resolving the problems of the deceived shareholders and in regulating the processes of reconstruction and development of Kazan and Moscow in 2015-2016.

Scientific novelty: considering the practice of the Russian state and municipal governance, the authors focus on the applied methods and procedures for its implementation, such as the creation of parallel management structures, the transition to the direct guidance regime, etc. Basing on the analysis of practical activities of bodies of the Russian Federation subjects, the authors revealed the ratio of the "manual" and "system" procedures in the administrative process, formulates the definition of "manual control", described the conditions and motives of its application, and concluded that the main reason for using and increasing the practice of "manual control" is the imperfection and inconsistency of the existing Russian legislation, which, on the one hand, does not fully reflect fundamental socio-economic changes what took place in Russia over the past decade and is not always able to adequately regulate the newly established relations between the subject and the object in the practice of public administration. Practical significance: as a result of their research, the authors predict the possible consequences of the emerging trend of increasing the practice of "manual control" of state-municipal authorities both medium- and long-term.

Keywords: Economics and economic management; "Manual" control; System management; Subject of management; Object of management; Balance of the direct and reverse links; Authorities; Direct guidance; Direct interaction of structures; Types of municipal management; Analysis of the "manual control" practice

\section{References}

1. Fayol, H. Administration industrielle et générale, Paris: Dunod, 1999 [1916], 133 p.

2. Follett, M. P. The new state: Group organization the solution of popular government, Penn State Press, 1918, 379 p.

3. Atamanchuk, G. V. Theory of state management: lecture course, Moscow: Omega-L, 2010, 525 p. (in Russ.).

4. Shlychkov, V. V. "Manual control" as a revelation of institutional crisis and deformation of the existing model of the Russian economy, Vestnik ekonomiki, prava i sociologii, 2015, No. 4, pp. 144-149 (in Russ.).

5. Prohorov, A. P. Russian model of management, 3-e izd., Moscow: Izd-vo Studii Artemija Lebedeva, 2014, 496 p. (in Russ.).

6. Shlychkov, V., Nestulaeva, D. Economic Science and Evolution of Economic Agents' Expectations Formation Process, Asian Social Science, 2015, vol. 11, No. 19, pp. 82-89. DOI:10.5539/ass.v11n19p82

7. King, S. D. Losing control: the emerging threats to Western prosperity, Yale University Press, 2010, 304 p.

8. Hasanova, A. Sh., Vedin, N. V. On the issue of forming the new economic paradigm, Vestnik ekonomiki, prava i sociologii, 2014, No. 4, pp. 106-111 (in Russ.).

9. Rjabow, A. Das Scheitern der demokratischen Transformation Russlands: war es unausweichlich?, Trendbericht Russland: Bilanz des letzten Jahrzehnts (1998-2008) und Perspektiven: ein Sammelband, Moscow: Rosspjen, 2010, pp. 248-271.

10. Isaev, A., Kadyshev, E. Forming the topical principles of state management and the regional economy regulation, Upravlenie ekonomicheskimi sistemami: elektronnyj nauchnyj zhurnal, 2012, No. 38, p. 5, available at: http://uecs.ru/uecs-38-382012/item/1049-2012-02-17-10-4649 (access date: 16.04.2016) (in Russ.).

11. North, D. C. Economic performance through time, The American economic review, 1994, vol. 84, No. 3, pp. 359-368.

12. Shlychkov, V. V., Khasanova, A. S., Vedin, N. V. A Quarter Century of Reform of the Russian Economy: is it Wandering in a Maze or Jogging in Place?, Indian Journal of Science and Technology, 2015, vol. 8, No. s (10). DOI:10.17485/ijst/2015/v8iS10/84883, available at: http:// www.indjst.org/index.php/indjst/article/view/84883/65853 (access date: 16.04.2016).

13. Bataykin, P. A., Khasanova, A. Sh., Shlychkov, V. V., Toumashev, A. R., Toumasheva, M. V. Economic Growth in the Conditions of Resource Constraints: Ordinal Approach to Optimization of Macroeconomic Production Structure, Journal of Applied Economic Sciences, 2016, vol. XI, No. 3 (41), pp. 521-531.

14. Aron, L. Russia's ‘Monotowns’ Time Bomb, American Enterprise Institute for Public Policy Research, October, 2009, vol. 19.

15. Teague, E. How did the Russian population respond to the global financial crisis?, Journal of Communist Studies and Transition Politics, 2011, vol. 27, No. 3-4, pp. 420-433.

16. Addison, J. T., Blackburn, M. L. Policy watch: The worker adjustment and retraining notification act, The Journal of Economic Perspectives, 1994, vol. 8, No. 1, pp. 181-190.

17. Bator, F. M. The anatomy of market failure, The quarterly journal of economics, 1958, pp. 351-379.

18. Hazen, T. L. Corporate Persona, Contract (and Market) Failure, and Moral Values, The NCL Rev., 1990, vol. 69, p. 273.

19. Coleman, J. L. Rational Choice Approach to Legal Rules, The Chi.-Kent L. Rev., 1989, vol. 65, p. 177.

20. Kraus, J. S., Coleman, J. L. Morality and the theory of rational choice, Ethics, 1987, vol. 97, No. 4, pp. 715-749.

21. Alafuzov, I. G. Public support as a key factor of efficiency of the anti-crisis measures of the Russian government, Vestnik ekonomiki, prava i sociologii, 2015, No. 1, pp. 13-15 (in Russ.).

22. Seregin, V., Shtykina, A., Tkachjov, I., Miljukova, Ja. Error 104: why the demolished Moscow buildings were admitted legal, available at: http://www.rbc.ru/ins/business/11/02/2016/56bc77f69a79477ba00be719 (access date: 18.02.2016) (in Russ.).

23. Avchenko, V. Complete APEC, // Expert Online. 09.09.2013, available at: http://expert.ru/2013/09/9/polnyij-ates/ (access date: 16.03.2016) (in Russ.).

24. Engels, F. Dialectics of nature / K. Marks, F. Engels. Sochinenija, Moscow: Politizdat, 1961, pp. 339-626 (in Russ.).

25. Batajkin, P. A. Directions of structural shifts in the national economy, Vestnik ekonomiki, prava i sociologii, 2012, No. 4, pp. $20-22$ (in Russ.).

26. Timofeev, R. A., Kulish, S. M. Forming the coopmplex potential of the regional economic system, Nauchnoe obozrenie, 2011, No. 3, pp. 3-11 (in Russ.) 
27. Tumashev, A. R., Tumasheva, M. V. Social-economic development of Russia and the tasks of investment policy, Ekonomicheskij vestnik Respubliki Tatarstan, 2014, No. 4, pp. 12-22 (in Russ.).

28. Gorschkow, M. Soziale und politische Wandlungen im Transformationsland Russland, Trendbericht Russland: Bilanz des letzten Jahrzehnts (1998-2008) und Perspektiven: ein Sammelband, Moscow: Rosspjen, 2010, pp. 406-420.

Received 21.06.2016

Accepted 28.08.2016

Available online 20.09.2016

(c) Shlychkov V. V., Kiyamov I. K., Kulish S. M., Nestulaeva D. R., Alafuzov I. G., 2016.

\section{Information about the authors}

Valeriy V. Shlychkov, Doctor of Economics, Professor, Professor of the Chair of Economic Theory, Kazan National Research University named after A. N. Tupolev

Address: 10 Karl Marx Str., 420111 Kazan, tel.: +7 (843) 238-15-93

E-mail: shlichkov valery@mail.ru

ORCID: http://orcid.org/0000-0002-3307-2153

Researcher ID: http://www.researcherid.com/rid/D-4695-2016

Ilgam K. Kiyamov, Doctor of Economics, Professor, Head of the Chair "Industrial Heat Energy Sector", Almetyevsk State Oil Institute Address: 2 Lenin Str., 423450 Almetyevsk, tel.: + 7 (8553) 31-00-04

E-mail: kiyamov.ilgam@mail.ru

ORCID: http://orcid.org/0000-0003-2955-777X

Researcher ID: http://www.researcherid.com/rid/L-7898-2016

Sergey M. Kulish, PhD (Economics), Associate Professor of the Chair of Management, Kazan State Energy University Address: 51 Krasnosel'skaya Str., 420066 Kazan, tel.: +7 (843) 519-42-91

E-mail:kulishsm@yandex.ru

ORCID: http://orcid.org/0000-0002-7392-1340

Researcher ID: http://www.researcherid.com/rid/D-4942-2016

Contact:

Diana R. Nestulaeva, $\mathrm{PhD}$ (Economics), Associate Professor of the Chair of Management, Kazan State Energy University

Address: 51 Krasnosel'skaya Str., 420066 Kazan, tel.: +7 (843) 519-42-91

E-mail: diana_n_r@mail.ru

ORCID: http://orcid.org/0000-0002-4885-449X

Researcher ID: http://www.researcherid.com/rid/ D-4945-2016

Igor G. Alafuzov, PhD (Economics), Deputy Editor-in-Chief, Journal "Bulletin of Economics, Law and Sociology" Address: 51a Karl Marx Str., 420015 Kazan, tel.: +7 (843) 238-15-93

E-mail: vestnik_eps@mail.ru

ORCID: http://orcid.org/0000-0001-8647-9603

Researcher ID: http://www.researcherid.com/rid/ D-4958-2016

For citation: Shlychkov V. V., Kiyamov I. K., Kulish S. M., Nestulaeva D.R., Alafuzov I. G. On some aspects of implementing the "manual control" by the bodies of the Russian state-municipal power, Actual Problems of Economics and Law, 2016, vol. 10, No. 3, pp. 39-54. DOI: http://dx.doi.org/10.21202/1993-047X.10.2016.3.39-54 